\title{
Fever without apparent sources in children: a nation-wide study in
} Japan

\author{
K Kasai ${ }^{1}$, M Mori ${ }^{2}$, R Hara ${ }^{2}$, T Miyamae ${ }^{* 2}$, T Imagawa ${ }^{2}$ and S Yokota ${ }^{2}$
}

Address: ${ }^{1}$ Department of Infectious Diseases and Rheumatology, Hyogo Prefectural Kobe Children's Hospital, Hyogo, Japan and ${ }^{2}$ Department of Pediatrics, Yokohama City University, Yokohama, Japan

* Corresponding author

from I5th Paediatric Rheumatology European Society (PreS) Congress

London, UK. 14-17 September 2008

Published: 15 September 2008

Pediatric Rheumatology 2008, 6(SuppI I):PI93 doi:I0.II86/I546-0096-6-SI-PI93

This abstract is available from: http://www.ped-rheum.com/content/6/SI/PI93

(c) 2008 Kasai et al; licensee BioMed Central Ltd.

\section{Background}

This study is addressed to implement a clinical decision support system for diagnostic management of children with fever without apparent sources.

\section{Patients and methods}

A questioner was sent to 2,843 hospitals to ask about patients with prolonged and/or recurrent fever without apparent sources in recent 5 years. The definition was as follows; 1) children with fever $>38^{\circ} \mathrm{C}$ for more than 2 weeks and with uncertain diagnosis in 1 week of evaluation during hospitalization, and 2) children with periodic fever.

\section{Results}

Among 960 cases fulfilled the definition. 828 (86\%) were diagnosed as having diseases of known causes. 190 (23\%) were infectious diseases (acute focal bacterial nephritis 31, cat-scratch disease 23 , urinary tract infection 20, osteomyelitis 9 and tuberculosis 8), 447 (54\%) were rheumatic diseases (JIA 221, vasculitis syndrome 39, inflammatory bowel diseases 34, SLE 25, and MCTD 12), 67 (8\%) were leukemia/malignancy (acute lymphatic leukemia 38, malignant lymphoma 9, neuroblastoma 4, Castleman disease 3). Autoinflammatory syndrome was diagnosed in 89 cases (PFAPA 45. FMF 17, CINCA 9, HIDS 9, and others). Other diseases included subacute necrotizing lymphadenitis, hemophagocytic syndrome, drug-induced fever, and ADEM.

\section{Conclusion}

Rare infectious diseases such as cat-scratch disease and tuberculosis were reminded in addition to routine investigation of infection. Along with these work-ups, malignancies and rheumatic diseases should be investigated. To have final diagnosis of auto-inflammatory syndrome, clinical characteristics such as fever pattern, skin rash, arthritis, and genetic analysis are needed. We established an algorism as a clinical decision support system for diagnosis. 